\title{
PENGUKURAN LAJU PAPARAN RADIASI PADA PERISAI RADIASI RUANG PANORAMIK DI INSTALASI RADIOLOGI RUMAH SAKIT ISLAM KLATEN
}

\author{
MEASUREMENT OF RADIATION EXPOSURE TO RADIATION SHEET OF \\ PANORAMIC SPACE IN RADIOLOGICAL INSTALLATION OF ISLAMIC HOSPITAL \\ KLATEN
}

\author{
Raih Sutejo ${ }^{1)}$ Siti Daryati ${ }^{2)}$ \\ ${ }^{1,2)}$ Health Polytechnics of Semarang-Indonesia \\ E-mail : raihthejo69@gmail.com
}

\begin{abstract}
Background: Research about the measurement of radiation exposure rate on panoramic radiation shield in Radiology Installation of Klaten Islamic Hospital has been conducted. The background of this research is in the panoramic room there is a veil that has a gap on the bottom as high as $20 \mathrm{~cm}$. The purpose of this research is to know the rate of radiation exposure on radiation panoramic shield in Radiology Installation of Klaten Islamic Hospital and the application of radiation protection system to the room.

Methods: This research type is quantitative with survey approach that is writer do observation, documentation and measurement of exposure rate of radiation at controlled and uncontrolled area by doing measurement at two state that is before exposure (background radiation) and after exposure. The data obtained are then analyzed descriptively to declare a safe examination room or not for workers and the general public by comparing the measurement results with UNSCEAR and NCRP report No. 147.

Result: The value of the background exposure rate in the panoramic chamber of the Klaten Hospital Radiology Installation exceeds the value of the background dose rate based on the location of the height of an area according to UNSCEAR. The background exposure value in the panoramic space ranges from 0.14 to $0.175 \mu \mathrm{Gy} /$ hour. The actual radiation exposure measurements at point $\mathrm{A}$ is $0.00021 \mathrm{mGy} / \mathrm{hour}$, point $\mathrm{B}$ is $0.000175 \mathrm{mGy} / \mathrm{h}$, point $\mathrm{C}$ is $0 \mathrm{mGy} /$ hour, point $\mathrm{D}$ is $0 \mathrm{mGy} /$ hour, point $\mathrm{E}$ is $0.000105 \mathrm{mGy} /$ hour, point $\mathrm{G}$ is $0,000735 \mathrm{mGy} /$ hour. These six results have not exceeded the NCRP report no. 147 is for controlled areas $0.0025 \mathrm{mGy} / \mathrm{hr}$ and uncontrolled area $0.0005 \mathrm{mGy} / \mathrm{hr}$.
\end{abstract}

Key word: measurement, display, panoramic

\section{PENDAHULUAN}

Pemanfaatan radisasi pengion telah banyak dimanfaatkan dalam kehidupan, salah satunya adalah dunia medis yang penerapanya melalui radiodiagnostik dan radioterapi. Penggunaan radiasi dibidang kesehatan bukan berarti tanpa efek samping, efek merugikan tersebut dapat terjadi apabila tubuh menerima paparan radiasi pengion dalam jumlah yang besar atau tidak memenuhi aturan standar yang berlaku. Dengan demikian diperlukan upaya secara terus menerus untuk melakukan pengendalian keselamatan dan kesehatan kerja radiasi melalui kegiatan proteksi radiasi berupa pemantauan paparan radiasi (Akhadi, 2000).

Keselamatan radiasi pengion diatur dan keamanan sumber radioaktif mengatur keselamatan radiasi terhadap pekerja, masyarakat, lingkungan hidup, keamanan sumber radioaktif dan inspeksi dalam pemanfaatan tenaga nuklir (PP No. 33 Tahun 2007). Menurut NCRP Report 147 Structural Design For Medical X-Ray Imaging Facilities, batasan nilai paparan radiasi dibagi menjadi dua yaitu daerah terkontrol nilai paparan radiasi sebesar $5 \mathrm{mGy} / \mathrm{tahun}$ atau 0,1 $\mathrm{mGy} /$ minggu dan daerah tidak terkontrol sebesar $1 \mathrm{mGy} /$ tahun atau $0,02 \mathrm{mGy} / \mathrm{ming}$ gu.

Menurut laporan penelitian UNSCEAR, secara rata-rata setiap orang menerima dosis $2,8 \mathrm{mSv}$ ( $280 \mathrm{mrem})$ per tahun, berarti seseorang hanya akan menerima sekitar setengah dari nilai batas dosis untuk masyarakat umum.
Panoramik adalah teknik pemeriksaan untuk meandapatkan gambaran gigi geligi berikut mandibular dan maxilla (Langland,1982). Persyaratan ruang pemeriksaan menurut Kemenkes No 1047 ruangan panoramik sendiri memiliki ketentuan dalam desain luas ruangan yaitu memiliki 3 Meter (panjang) x 2 Meter (lebar) x 2,8 Meter (tinggi), ketebalan dinding $25 \mathrm{~cm}$ (dua puluh lima sentimeter) bata merah atau beton $20 \mathrm{~cm}$ (dua puluh sentimeter) atau setara 2 $\mathrm{mm}$ pb dan tabir minimal $200 \mathrm{~cm}$ (t) x $100 \mathrm{~cm}$ (l) setara $2 \mathrm{~mm}$ $\mathrm{pb}$, ukuran kaca sesuai kebutuhan tebal $2 \mathrm{~mm}$ pb (Permenkes No 1014, 2008).

Berdasarkan observasi tidak terstruktur penulis, ruangan panoramik di Instalasi Radiologi RSI Klaten memiliki luas 6 Meter (panjang) x 4 Meter (lebar) x 2,8 Meter (tinggi) ruang tersebut dilengkapi dengan tabir, namun bagian bawah tabir tidak tertutup atau terdapat celah, selain itu pintu ruang panoramik di Rumah Sakit Islam Klaten tidak dapat tertutup dengan rapat sehingga dikhawatirkan adanya peluang kemungkinan kebocoran pada pintu dan prisai meski tidak terlihat.

\section{METODE}

Jenis penelitian yang digunakan dalam penelitian ini adalah penelitian kuantitatif dengan pendekatan survey yaitu penulis melakukan pengamatan dan pengukuran laju paparan di lokasi penelitian untuk mengetahui tingkat keamanan 
ruangan pemeriksaan dengan cara membandingkan data yang diperoleh dari hasil pengukuran dengan ketentuan NCRP, 2004 yang kemudian dijadikan pembahasan lebih lanjut lalu ditarik kesimpulan.

\section{HASIL}

Penelitian dilakukan dengan melakukan observasi pada ruang pemeriksaan panoramik di Instalasi Radiologi Rumah Sakit Islam Klaten. Observasi yang dilakukan meliputi pengamatan langsung terhadap ukuran, karakteristik ruang pemeriksaan dan sistem proteksi radiasi yang diterapkan. Ruang pemeriksaan berbentuk persegi panjang dengan ukuran $6 \mathrm{~m}(\mathrm{p}) \times 4 \mathrm{~m}$ (1) x 2,8 m (t) dalam satu bulan dilakukan pemeriksaan sebanyak 80 pemeriksaan. Dinding ruang pemeriksaan terbuat dari bata merah dilapisi keramik dengan tebal $30 \mathrm{~cm}$ seperti pada gambar 1, sedangkan titik-titik pengukuran dapat dilihat pada gambar 2 .

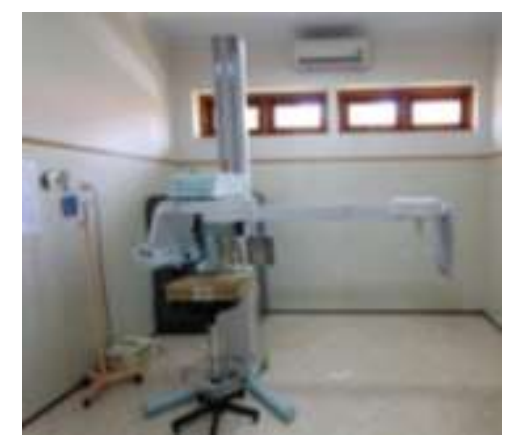

Gambar 1. Gambar Pesawat Panoramik

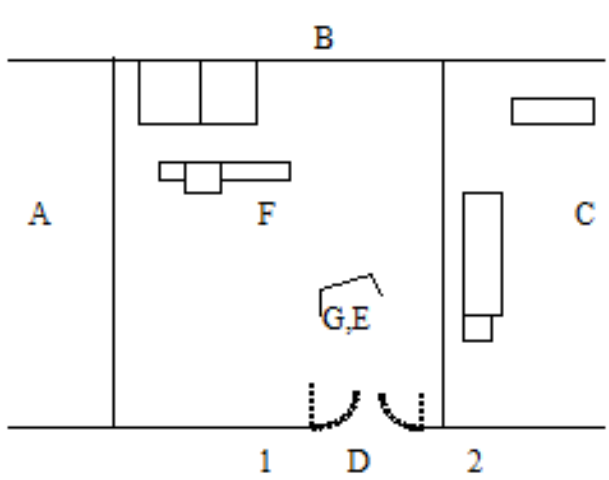

Keterangan :

A. Titik pengukuran pertama berada didalam ruang dokter jaga

B. Titik pengukuran kedua berada di luar tembok ruang

C. Titik ketiga pengukuran berada didalam ruang USG

D. Titik keempat pengukuran dibalik pintu ruang panoramik

E. Titik kelima, keenam pengukuran dibalik dan celah tabir ruang panoramik

F. Sumber radiasi

1,2 . Ruang tunggu pasien

Gambar 2. Denah ruang panoramik dan titik pengukuran

Ruang ini dilengkapi 2 pintu kayu setebal $6 \mathrm{~cm}$ dengan dilapisi pb setebal $2 \mathrm{~mm}$. Dalam ruang pemeriksaan panoramik terdapat perisai dari kayu dilengkapi timbal $2 \mathrm{~mm}$ yang berukuran tinggi $180 \mathrm{~cm}$ lebar $103 \mathrm{~cm}$ dengan tebal 5 $\mathrm{cm}$. Perisai memiliki celah pada bagian bawah setinggi $20 \mathrm{~cm}$ dari lantai yang memungkinkan terjadinya kebocoran paparan radiasi. Upaya proteksi radiasi pada ruang pemeriksaan panoramik dilakukan dengan memasang lampu tanda eksposi di depan pintu dan pemasangan poster tanda radiasi.

Instalasi Radiologi Rumah Sakit Islam Klaten terletak pada daerah dengan ketinggian 75 meter diatas permukaan laut (UU No. 1/1950). Pengukuran laju paparan radiasi dilakukanV dengan menggunakan alat surveymeter babyline pada dua keadaan yaitu sebelum eksposi dan sesudah eksposi. Faktor eksposi yang digunakan 75 kV, 10 mA, 17 Sec dengan menggunakan phantom kepala setinggi $120 \mathrm{~cm}$ dari lantai.

Paparan radiasi latar (background) pada ke lima titik di Instalasi Radiologi Rumah Sakit Islam Klaten termasuk dalam kategori 0 meter diatas permukaan laut yang memiliki laju dosis antara 0,14 - 0,175 $\mu \mathrm{Sv} / \mathrm{jam}$. Adapun hasil konversi pengukuran Laju Paparan seperti pada tabel 1

\begin{tabular}{cc} 
Tabel 1. Hasil Konversi Pengukuran Laju Paparan Radiasi \\
\hline $\begin{array}{c}\text { Titik } \\
\text { Pengukuran }\end{array}$ & $\begin{array}{c}\text { Konversi hasil pengukuran } \\
\text { (mGy/jam) }\end{array}$ \\
\hline $\mathrm{A}_{\text {DTT }}$ & 0,00021 \\
$\mathrm{~B}_{\text {DTT }}$ & 0,000175 \\
$\mathrm{C}_{\text {DTT }}$ & 0 \\
$\mathrm{D}_{\text {DTT }}$ & 0 \\
$\mathrm{E}_{\text {DT }}$ & 0,000105 \\
$\mathrm{G}_{\text {DT }}$ & 0,000735 \\
\hline
\end{tabular}

DT $=$ Daerah Terkontrol

DTT $=$ Daerah Tidak Terkontrol

Paparan radiasi sesungguhnya (setelah dikonversi menjadi $\mathrm{mGy} / \mathrm{jam}$ ) titik A $0,00021 \mathrm{mGy} / \mathrm{jam}$, titik B sebesar 0,000175 mGy/jam, titik C sebesar $0 \mathrm{mGy} / \mathrm{jam}$, titik D sebesar $0 \mathrm{mGy} / \mathrm{jam}$, titik E sebesar 0,000105 mGy/jam, titik $\mathrm{G}$ sebesar $0,000735 \mathrm{mGy} / \mathrm{jam}$

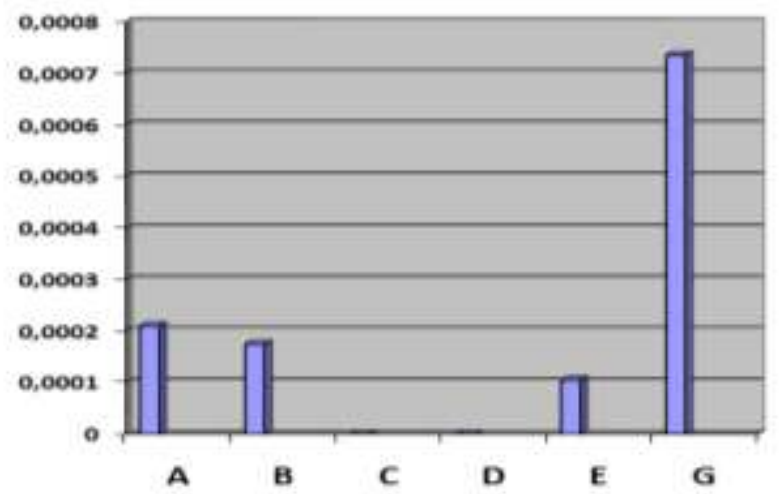

Gambar 3. Grafik pengukuran laju paparan radiasi pada perisai radiasi ruang panoramik instalasi radiologi Rumah Sakit Islam Klaten

Gambar 3 menunjukkan grafik pengukuran laju paparan radiasi pada perisai radiasi ruang panoramik instalasi radiologi Rumah Sakit Islam Klaten sehingga dapat dilihat titik tertinggi adalah titik $\mathrm{G}$ sebesar $0,000735 \mathrm{mGy} / \mathrm{jam}$ dan titik terendah adalah titik $\mathrm{C}$ dan $\mathrm{D}$ sebesar $0 \mathrm{mGy} / \mathrm{jam}$ 


\section{DISKUSI}

Instalasi Radiologi Rumah Sakit Islam Klaten terletak pada daerah dengan ketinggian 75 meter diatas permukaan laut (UU No. 1/1950). karakteristik ruang pemeriksaan dan sistem proteksi radiasi yang diterapkan. Ruang pemeriksaan berbentuk persegi panjang dengan ukuran $6 \mathrm{~m}$ (p) x $4 \mathrm{~m}$ (l) $\mathrm{x}$ 2,8 m (t) dalam satu bulan dilakukan pemeriksaan sebanyak 80 pemeriksaan. Dinding ruang pemeriksaan terbuat dari bata merah dilapisi keramik dengan tebal $30 \mathrm{~cm}$. Ruang ini dilengkapi 2 pintu kayu setebal $6 \mathrm{~cm}$ dengan dilapisi pb setebal $2 \mathrm{~mm}$.Pengukuran laju paparan radiasi dilakukan dengan menggunakan alat surveymeter babyline pada dua keadaan yaitu sebelum eksposi dan sesudah eksposi.

Paparan radiasi latar (background) pada ke lima titik di Instalasi Radiologi Rumah Sakit Islam Klaten termasuk dalam kategori 0 meter diatas permukaan laut yang memiliki laju dosis antara $0,14-0,175 \mu \mathrm{Sv} / \mathrm{jam}$. Hal tersebut melebihi dari ketentuan UNSCEAR (2000) berdasarkan lokasi dan ketinggian suatu daerah. Menurut penulis paparan radiasi yang terukur dapat berasal dari radiasi kosmik dimana radiasi ini dapat berasal dari luar angkasa dalam bentuk radiasi kosmis maupun dari permukaan bumi, udara, air dan bahkan dari tubuh manusia sendiri.

Dari hasil pengukuran saat eksposi (dibandingkan dengan NCRP) titik A,B,C,D yang merupakan daerah tidak terkontrol belum melampaui batas yang di tentukan NCRP yaitu 0,0005 mGy/jam, sedangkan titik $E$ dan $G$ yang merupakan daerah terkontrol belum melampaui batas yang ditentukan NCRP yaitu $0,0025 \mathrm{mGy} / \mathrm{jam}$.

Titik $G$ yang memiliki nilai laju paparan paling tinggi jika dibandingkan dengan titik lain, hal ini karena titik $G$ berada pada celah tabir yang tidak tertutup oleh pb, sehingga memungkinkan kaki terkena paparan radiasi. Nilai paparan yang diterima oleh kaki dapat dihitung dari perhitungan nilai laju paparan titik G (0,000735 mGy/jam) dikali lama penyinaran (17 detik) dikali banyaknya pemeriksaan setiap bulan (80 kali) dikali satu tahun (12 bulan). Sehingga diperoleh hasil sebesar 11,91 mGy/tahun Perhitungan diatas menunjukan bahwa satuan mGy dengan $\mathrm{mSv}$ memiliki nilai sama sehingga hasil tersebut belum melebihi Nilai Batas Dosis pekerja radiasi sebesar $500 \mathrm{mSv} /$ tahun untuk kaki dan kulit.

Hasil pengukuran laju paparan masih dalam batas normal karena tidak melebihi ketentuan NCRP dan NBD, angka yang di tunjukan pada titik A,B,D,E,G dapat disebabkan oleh berbagai faktor seperti jarak dan perisai radiasi. Semakin jauh jarak pengukuran dengan sumber radiasi maka radiasi akan semakin kecil begitu sebaliknya dan semakin tebal atau semakin rapat struktur perisai radiasi maka semakin kecil radiasi yang dapat melewati tabir tersebut. Akan tetapi meskipun hasil pengukuran laju paparan radiasi belum melampaui ketentuan, perlu diwaspadai akan efek stokastik yang tidak mengenal adanya dosis ambang sehinggga sekecil apapun dosis radiasi yang diterima tubuh ada kemungkinan akan menimbulkan kerusakan sel somatik maupun genetik.

\section{SIMPULAN}

Instalasi Radiologi Rumah Sakit Islam Klaten termasuk dalam kategori 0 meter diatas permukaan laut, pada ke lima titik pengukuran memiliki nilai laju paparan latar (background) antara 0,14 - 0,175 $\mu \mathrm{Sv} / \mathrm{jam}$. Hal tersebut melebihi dari ketentuan UNSCEAR (2000) berdasarkan lokasi dan ketinggian suatu daerah yaitu $0,03 \mu \mathrm{Sv} / \mathrm{jam}$. Hasil pengukuran laju paparan sesungguhnya setelah eksposi pada keenam titik menunjukan hasil yang berbeda-beda, titik A,B,C,D yang merupakan daerah tidak terkontrol belum melampaui batas yang di tentukan NCRP yaitu 0,0005 $\mathrm{mGy} / \mathrm{jam}$, sedangkan titik E dan $\mathrm{G}$ yang merupakan daerah terkontrol belum melampaui batas yang ditentukan NCRP yaitu $0,0025 \mathrm{mGy} / \mathrm{jam}$. Titik $\mathrm{G}$ yang berada pada celah tabir berbatasan langsung dengan kaki sehingga memungkinkan kaki terkena paparan radiasi sebesar 11,91 mGy/tahun. Hasil tersebut belum melebihi Nilai Batas Dosis pekerja radiasi sebesar $500 \mathrm{mSv} /$ tahun untuk kaki dan kulit.

Ruang pemeriksaan panoramik di Instalasi Radiologi Rumah Sakit Islam Klaten memiliki ukuran 6 m (p) x 4 m (l) $\mathrm{x} 2,8 \mathrm{~m}(\mathrm{t})$ dan struktur dinding terbuat dari bata merah dengan keramik setebal $30 \mathrm{~cm}$ serta pintu setebal $6 \mathrm{~cm}$ yang terbuat dari kayu yang dilapisi timbal (pb), hal ini menunjukan ruang telah sesuai ketentuan PERMENKES No. 1014.MENKES/SK/XI/2008 tentang syarat ruang pemeriksaan yaitu $4 \mathrm{~m}$ (p) x $3 \mathrm{~m}$ (l) $\times 2,8 \mathrm{~m}$ (t) dan struktur dinding yang terbuat dari batu bata merah dengan ketebalan $25 \mathrm{~cm}$ atau setara $2 \mathrm{~mm}$ pb.

\section{DAFTAR PUSTAKA}

Akhadi, M. 2000. Dasar-dasar Proteksi Radiasi. PT. Rineka Cipta : Jakarta.

Bapeten. 2011. Proteksi Radiasi. Peraturan Kepala (Perka) No. 8 Tahun 2011.

Ballinger, Philip W. 1995. Radiographic Positioning and Radiologic Procedures, 8th Ed. St Louis: Mosby.

Haditjahyono, Hendriyanto. 2006. Pusdiklat Batan Jakarta. http://www.batan.go.id/pusdiklat/Pengukuran_Radiasi/Proteksi_02 .htm

Keputusan Menteri Kesehatan. 2009. Pedoman Kendali Mutu (QC) Peralatan Radiodiagnostik, no.1250/MENKES/SK/XII/2009

Martem, Milvita, Yuliati, Kusumawati. 2015. Pengukuran Dosis Radias Ruangan Radiologi II Rumah Sakit Gigi Dan Mulut (RSGM) Baiturrahmah Padang Menggunakan Surveymeter Unfors-XI.

NCRP. 2004. Structural Shielding Design for Medical X-ray Imaging Facilities.

Permenkes. 2008. Standar Pelayanan Radiologi Diagnostik di Sarana Pelayanan Kesehatan. PERMENKES No. 1014/MENKES/SK /XI/2008. Jakarta.

Peraturan Pemerintah No 33 Tahun 2007. Tentang Radiasi Pengian dan Kesalamatan Sumber Radioaktif.

Rassad, S. 2005. Radiologi Diagnostik Balai Penerbit Fakultas Kedokteran Universitas Indonesia. Jakarta

Statkeiwicz, M, Kussel, E. 2000. Radiation Protection for Student Radiographer. CV Mosby Company : St Louis.

Suryopratomo,K, Widiharto, A. 1998. Dasar Fisika Pelatihan Petugas Proteksi Radiasi. Jurusan Teknik Nuklir Fakultas Teknik Universitas Gajah Mada Yogyakarta.

United Nations Scientific Commite on the Effects of Atomio Radiation (UNSCEAR). 2000. Exposure from Natural Sources Ofradiation. 